\title{
Intra Oral Versus External Approach in the Surgical Management of Eagle's Syndrome
}

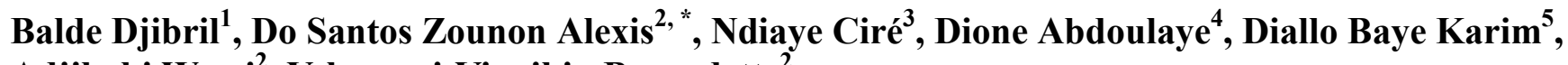 \\ Adjibabi Wassi ${ }^{2}$, Yehouessi-Vignikin Bernadette ${ }^{2}$ \\ ${ }^{1}$ ENT-CFS Department, Regional Hospital Heinrich Lubke, Diourbel, Sénégal \\ ${ }^{2}$ ENT-CFS Department, Faculty of Health Sciences, University of Abomey Calavi, Cotonou, Bénin \\ ${ }^{3}$ ENT-CFS Department, University Hospital Center of Fann, Dakar, Sénégal \\ ${ }^{4}$ Radiology Department, University Hospital Center of Fann, Dakar, Sénégal \\ ${ }^{5}$ ENT Department, Albert Royer Hospital Center Fann, Dakar, Sénégal \\ Email address: \\ azdosantos@yahoo.fr(Do S. Z. Alexis) \\ ${ }^{*}$ Corresponding author
}

\section{To cite this article:}

Balde Djibril, Do Santos Zounon Alexis, Ndiaye Ciré, Dione Abdoulaye, Diallo Baye Karim, Adjibabi Wassi, Yehouessi-Vignikin Bernadette. Intra Oral Versus External Approach in the Surgical Management of Eagle's Syndrome. International Journal of Otorhinolaryngology. Vol. 5, No. 1, 2019, pp. 9-14. doi: 10.11648/j.ijo.20190501.13

Received: January 16, 2019; Accepted: March 2, 2019; Published: March 21, 2019

\begin{abstract}
Eagle syndrome is defined as an elongation of the styloid process. It is a radioclinic entity characterized by heterogeneous polymorphic symptomatology. Its management is essentially through intra oral or external surgery. The objective of our work is to highlight the various diagnostic means and to propose a surgical therapeutic attitude on the clinical and radiological basis. This is a retrospective study performed at the ENT department of the Heinrich Lübké Hospital in Diourbel between March 2015 and March 2017. The study involved 15 patients with confirmed Eagle's syndrome based clinical and computed tomography evidence. Epidemiological, diagnostic and therapeutic data were collected from patient records and the Operative Record register. The choice of the surgical approach was based on Langlais' classification, the measurement of the styloid process and the complications. The study included 15 patients, counting 14 women and one man with a sex ratio (male / female) of 0.071 . The age of the patients varied between 23 years and 55 years with an average of 31.33 years. The chief complaints were foreign body sensation in the throat (15 patients, 100\%), headache (15 patients, 100\%), dysphagia (11 patients, 66.6\%), neck pain (6 patients; $40 \%$ ), periorbital and temporal pain ( 5 patients, $33.33 \%$ ), otalgia with tinnitus (4 patients, $26.66 \%$ ). The average size of the styloid process was $4.085 \mathrm{~cm}$ (1.608 inches). Only one patient received exclusively medical treatment. The others received surgical treatment by external approach (9 patients, $64.3 \%)$ or intra-oral approach after prior tonsillectomy (5 patients, 35.7\%). The styloidectomy was bilateral in 10 patients (71.14\%) and unilateral in 4 patients $(28.57 \%)$. Eagle syndrome is a condition considered rare. Its curative treatment is essentially surgical with an intraoral or external approach. We recommend the external approach because it offers a better exposure of the operative field, and control of the cervical neurovascular elements. The external approach generates little postoperative pain thereby shortening the period of hospitalization.
\end{abstract}

Keywords: Eagle Syndrome, Surgical Approach, Styloid Process

\section{Introduction}

Eagle syndrome is defined as an elongation of the styloid process or calcification of the stylohyoid ligament measuring more than 2.5 centimeters. It was first described by W Eagle in 1935. It is a radioclinical entity characterized by heterogeneous and polymorphic symptomatology. Because of its non-specific symptomatology, it is underestimated and sometimes leads to misdiagnosis. It can be complicated by ischemic stroke $[1,2]$. Elongation of the styloid process is quite frequent with a prevalence of 19.4 to $52.1 \%$; of which 
only $6 \%$ are symptomatic [3]. Although approximately $4 \%$ of the population is thought to have an elongated styloid process, only between $4 \%$ and $10.3 \%$ of this group is symptomatic [4-6]. Therefore, the actual incidence of Eagle's syndrome is $0.16 \%$ [3]. The diagnosis is essentially confirmed through a CT scan. The cut-off value commonly used to define a long styloid process is $30 \mathrm{~mm}[4,7,8]$. Its surgical management requires either an intraoral approach or an external approach. Fillipo Montevecchi et al [c] reported an experience with a bilateral robotic- assisted styloidectomy. This procedure is a safe alternative to traditional chirurgical approaches granting an excellent view and a safe manipulation by robotic arms, and, thereby avoiding iatrogenic damage to neurovascular strucures. The objective of our work is to highlight the various diagnostic means and to propose a surgical therapeutic attitude on clinical and radiological basis.

\section{Material and Method}

This is a retrospective study performed at the ENT

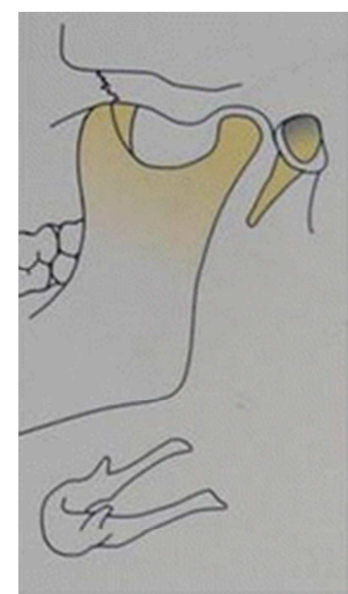

Normal Styloid

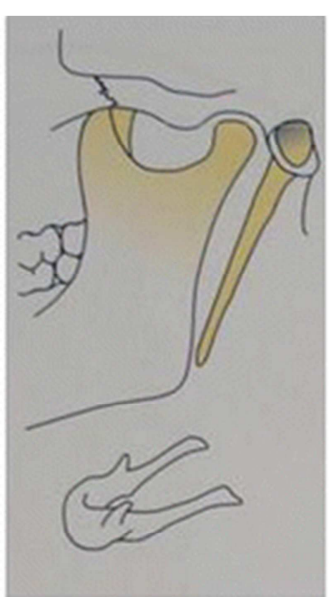

Type I

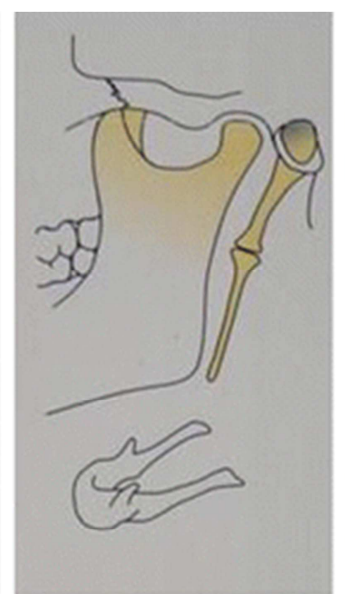

Type II department of the Heinrich Lübké Hospital in Diourbel between March 2015 and March 2017. The study involved 15 patients treated medically or surgically for an Eagle syndrome. An investigation sheet allowed for the collection of data from the patient files and the operative record logbook. The data collected were epidemiological (age, sex), diagnostic (complaints, physical examination, CT measurements of the styloid process), and therapeutic (type of treatment, approach, per operative and post-operative complications). Patients were divided according to the Langlais' classification into three types depending on whether or not the styloid process was continuous (Figure 1 \& 2):

1. Type 1: there is no interruption in the continuity of the styloid process

2. Type 2: there is a pseudo articulation between the styloid process and stylohyoid ligament

3. Type 3: there are multiple interruptions of the continuity of the styloid process or of the calcified stylohyoid ligament creating a multiple pseudo joint.

Figure 1. Langlais classification according to Chamdramani B More [5].
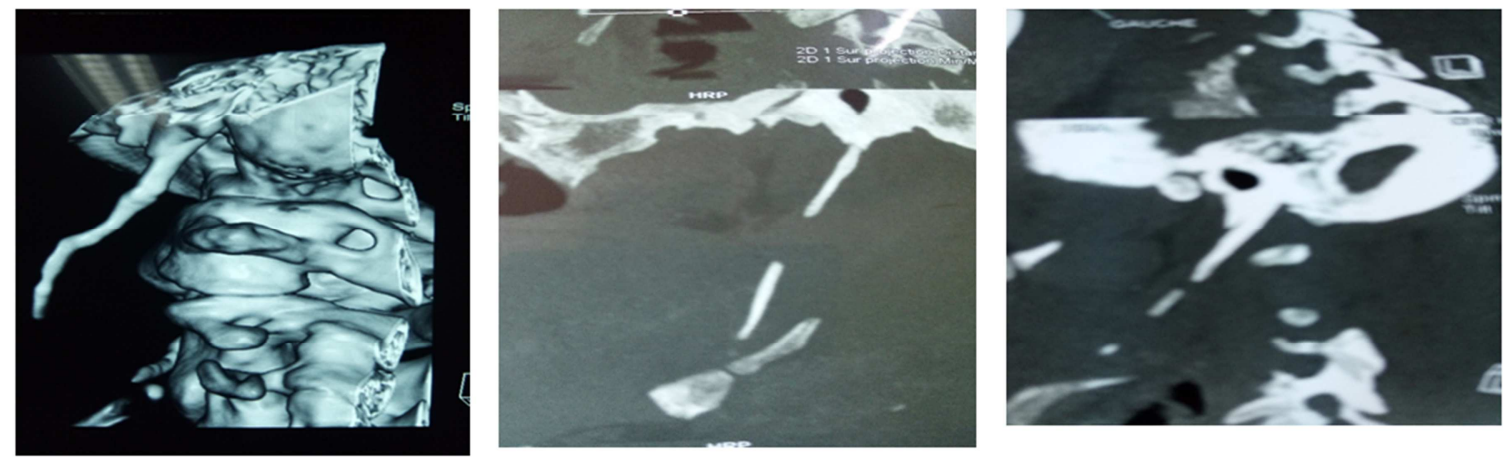

Figure 2. Scannographic images of the Langlais classification of Eagle syndrome according to our study.

\section{Results}

\subsection{Epidemiological Aspects}

We gathered 15 patients over a two-year period, an annual hospital prevalence of 7.5 patients per year. There were 14 women and one man, a sex ratio (male / female) of 0.071 . The age ranged from 23 years to 55 years with an average of 31.33 years. 


\subsection{Diagnostic Aspects}

The chief complaints were: oropharyngeal foreign body sensation (15 patients, $100 \%)$, headache (15 patients, $100 \%)$, dysphagia (11 patients, $66.6 \%$ ), neck pain (6 patients, $40 \%$ ), periorbital and temporal pain (5 patients, $33.33 \%$ ), earache with tinnitus (4 patients, 26.66\%) [table1].

Table 1. Chief complaints.

\begin{tabular}{lll}
\hline Chief complaints & Number & $\mathbf{\%}$ \\
\hline Oropharyngeal foreign body sensation & 15 & 100 \\
Headache & 15 & 100 \\
Dysphagia & 11 & 66,66 \\
Neck pain & 6 & 40 \\
Periorbital and temporal pain & 4 & 33,33 \\
Otalgia + tinnitus & 4 & 33,33 \\
\hline
\end{tabular}

The somatic ENT examination was normal in all symptomatic patients apart from the pain on palpation of palatine tonsils found in 10 patients (66.66\%).

Computed tomography of styloid processes with 3dimensional reconstruction was performed in all patients. It confirmed the diagnosis by accurately measuring the length of styloid processes. The length of the styloid processes ranged from $2.87 \mathrm{~cm}$ to $7.5 \mathrm{~cm}$ with an average of $4.085 \mathrm{~cm}$. The elongation of the styloid processes was bilateral in 10 cases $(66.66 \%)$ and unilateral in 5 cases $(33.33 \%)$ [Table 2].

Table 2. CT scan measurements of styloid processes in centimeters.

\begin{tabular}{lll}
\hline Patients & Right & Left \\
\hline 1 & 2,85 & 2,90 \\
2 & 3,20 & 3,80 \\
3 & 4,20 & 4 \\
4 & 2,9 & 3,20 \\
5 & 7 & 4,3 \\
6 & 4,5 & 4,3 \\
7 & 5 & 3 \\
8 & 3,4 & 2,90 \\
9 & 4,90 & 4,3 \\
10 & 2,83 & 4 \\
11 & 4,2 & 4,6 \\
12 & 7,5 & 2,52 \\
13 & 2,5 & 2,86 \\
14 & 2,4 & 3,02 \\
15 & 2 & 4,75 \\
\hline
\end{tabular}

Based on Langlais' classification, patients were divided into type 1 ( 8 patients), type 2 (5 patients), and type 3 (2 patients).

\subsection{Therapeutic Aspects}

For one of the patients the treatment was exclusively medical based on anti-inflammatory drugs (Diclofenac 150 $\mathrm{mg}$ twice a day for 10 days). Management was surgical for the other 14 patients. The surgical approach was either through intra-oral route or external route. The choice of surgical approach in the management of our patients was based on the Langlais' classification, the size of the styloid, as well as foreseeable per and postoperative complications. We used the external route for 9 patients $(64.3 \%)$ and the intraoral route following prior tonsillectomy for 5 patients
$(35.7 \%)$. The styloidectomy was bilateral in 10 patients (71.14\%) and unilateral in 4 patients $(28.57 \%)$.

The same surgical team treated the patients using one of the two following surgical techniques:

The intra oral route's technique: The technique consists of first performing a tonsillectomy. Then infiltrate 5 milliliters of $1 \%$ xylocaine adrenaline into the tonsillar lodge. Locate the tip of the styloid process in the tonsillar lodge by palpation with the fingers. Once the tip is located, dissect the styloid process while following its path. In order to do this, open the pharyngo basilar fascia and retract the upper and middle constrictor muscle. Through the rest of the dissection, palpate the tonsillar lodge from time to time to navigate. This palpation helps identify the carotid artery and avoid it. Once the entire styloid process is seen and stripped, the resection of its tonsillar lodge's portion is performed with a pair of scissors (Figure 3).
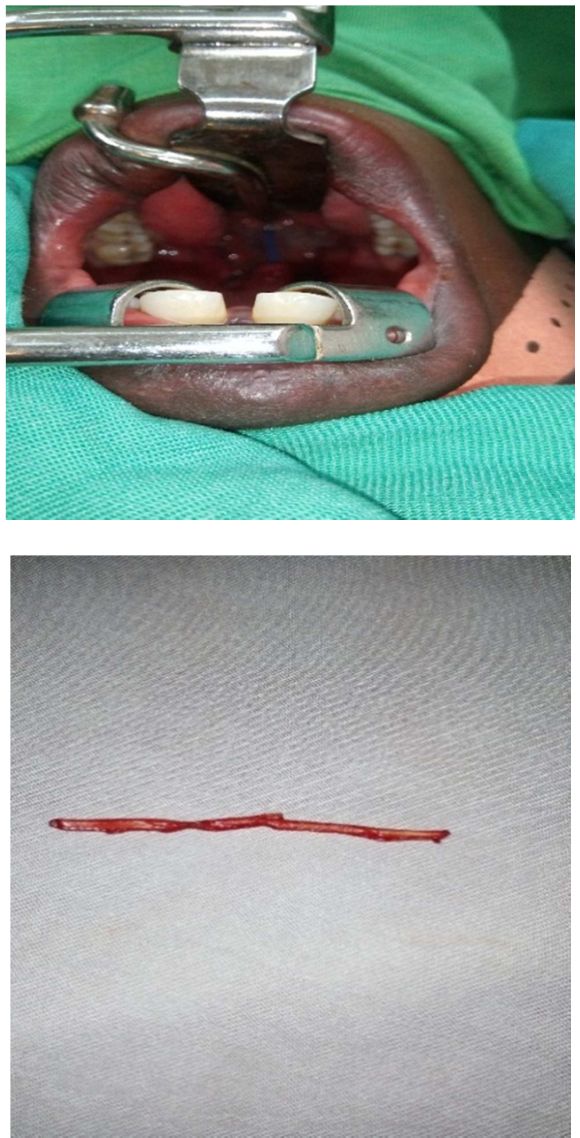

Figure 3. Approaching the styloid process by intra-oral route following a tonsillectomy.

The external route's Technique: This technique consists in approaching the styloid process the same way as in a parotidectomy. A Redon's bayonet-shaped incision is made consisting of three segments. The first segment of incision will be vertical pre-auricular ranging from the root of the helix to the level of the lobule of the auricle, the second segment of incision will complete the first while bypassing the lobule and stop at the anterior border of the sternocleidomastoid muscle just at its mastoid insertion. The 
third segment will complete the second, bordering the anterior edge of the sternocleidomastoid muscle. The flap is detached from under the platysma muscle up to the level of the anterior edge of the masseter muscle. Next, release the posterior border of the parotid gland from the external auditory canal and the sternocleidomastoid muscle. The trunk of the facial nerve is sought in the angle formed by the external auditory canal and the posterior belly of the digastric muscle. Once the trunk of the facial nerve is identified; palpate using a finger, the styloid process under the nerve and within the space formed by the forward reclined gland by a retractor and back by the sterno-cleido-mastoid muscles and the stylopharyngeus muscle. The styloid process will be dissected all along its path while entirely denuded. The palpation will always be repeated as many times as necessary. It will safely track the styloid process. Then, we will perform the total styloidectomy at the base of the process while checking the facial nerve (Figure 4).
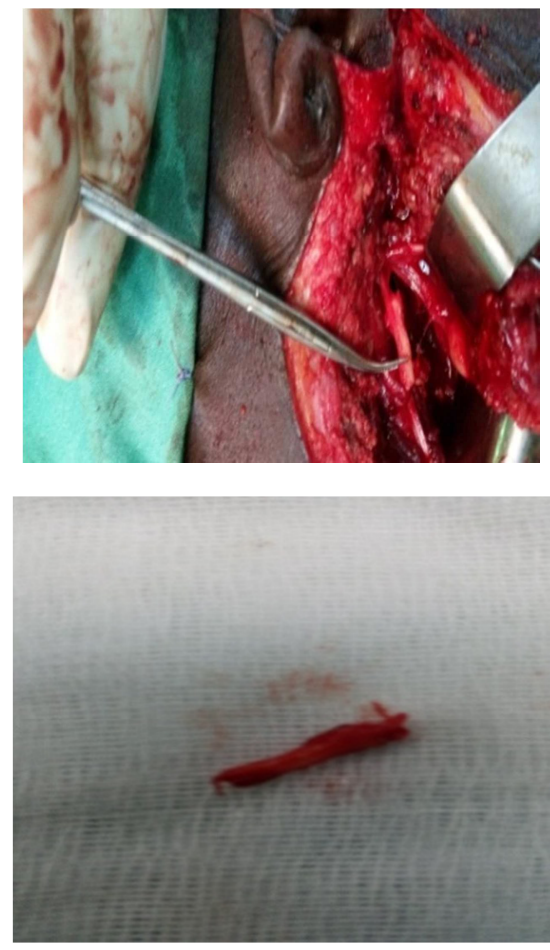

Figure 4. Approaching the styloid process by external route.

No perioperative complication was recorded for both techniques. On the other hand we encountered some difficulties in the exposure and the dissection while performing the intra oral technique. For one of the patients, the initial approach which was intra oral technique had to rapidly be converted to the external technique because of the poor exposure of the operative field. The external route gave us more exposure and allowed better control of the large vessels of the neck and the facial nerve during dissection.

Postoperative complications were essentially transient peripheral facial paralysis in 3 patients $(20 \%)$. This paralysis totally regressed after 10 days of oral anti-inflammatory treatment.

The comparison between the two approaches was also based on the following elements: (Table 3 )

(a) The duration of surgery: it was an average of 30 minutes (give or take 10 minutes) for the intra-oral route and 40 minutes (give or take10 minutes) for the external route

(b) Pain: More intense when the intraoral route is used, ranking up to a 7/10 on the Visual Analog Scale of pain intensity (VAS), and lasted up to 2 weeks. For patients who were treated with an external route technique, the pain was moderate (VAS $=2 / 10$ on average) and lasted about 3 days.

(c) Scarring: Exclusively related to the external route technique. Scars disappeared after 2 months and remained disseminated.

(d) The hospitalization stay period: it was 5 days (give or take 2 days) long for the intra-oral route and 1 day long for the external route.

(e) The healing time: it was 15 days (give or take 3 days) for the intra-oral route and 7 days (give or take 2 days) for the external route.

Table 3. Comparison of the two surgical approaches in the management of Eagle's syndrome.

\begin{tabular}{lll}
\hline Criteria & Intraoral route & External route \\
\hline Pain & Very intense & Low \\
Scarring & None & Noticeable \\
Hospital stay duration & $5 \pm 2$ days & 1 day \\
Healing time & $15 \pm 3$ days & $7 \pm 2$ days \\
Surgery time & $30 \pm 10$ Minutes & $40 \pm 10$ Minutes \\
Peroperative Surgical field & Poor & Good \\
exposure & & \\
\hline
\end{tabular}

\section{Discussion}

\subsection{Epidemiological Aspects}

Eagle Syndrome is a condition considered rare. However, it is not as rare as we think. We believe that it is under diagnosed and undervalued because its varied and polymorphic cervico-facial symptomatology misleads the diagnosis. In two years, we collected 15 cases of Eagle syndrome that were all symptomatic.

We recorded a very high female predominance (14 women and $1 \mathrm{man}$ ), a sex ratio of 0.075 . The age of patients ranged from 23 years to 55 years with an average age of 33.33 years. Ankit $\mathrm{A}$ and al [9] also reported a female predominance with 16 women for every 10 men. According to Ankit, 53, 85\% of these patients were in their fifties and the of age extremes were 22 years old and 68 years old [9]. These results are similar to those found in our series. The frequency of Eagle syndrome is estimated to $4 \%$ of the general population, and only $4 \%$ of these ossifications are symptomatic [10].

\subsection{Diagnostic Aspects}

Multiple functional signs may coexist or present in the symptomatology of Eagle syndrome. The main chief complaints are: oropharyngeal foreign body sensation, headache, dysphagia, earache, tinnitus, periorbital pain, neck 
pain. All of these symptoms may coexist or be individually present. The characteristic fact is that this symptomatology occurs in a context of normal ENT somatic examination apart from the unsteady pain upon palpation of the palatine tonsils on the ill side (pathognomonic sign). Since this sign is not constant, its absence does not exclude the diagnosis of Eagle syndrome. In our series, palpation of the tonsils was sensitive in 10 out of 15 patients. Several other authors found the same symptoms with almost constant dysphagia and foreign body sensation in the throat [3, 10-18]. According to Haluk Y and al [19], the anterior angulation and the length of the styloid apophysis are responsible for symptoms in Eagle syndrome. According to Piagkou M [20], the Eagle syndrome is underestimated while its clinical symptomatology remains important. It must be considered when facing cases presenting cervico-facial symptomatology with normal clinical examination. Anh D and al [1] reported a case of pseudo aneurysm of the external carotid artery related to Eagle syndrome. Several cases of internal carotid artery dissection caused by a long styloid process were published by Elike $\mathrm{H}$ [21] and Yoshifumi N [22]. Farhat HI and al reported a case of ischemic stroke caused by Eagle syndrome [2]. Several cases of internal carotid artery dissection caused by a long styloid process were published [21, 22]. Computed tomography of styloid processes with three-dimensional reconstruction (or sometimes CT angiography) is the key examination to confirm the diagnosis, to accurately measure the length of the styloid process, to determine its relationship with neighboring vascular structures and appreciate it's reclining. In our study, the length of the styloid processes ranged from $2.87 \mathrm{~cm}$ to $7.5 \mathrm{~cm}$ with an average of $4.085 \mathrm{~cm}$. The elongation of the styloid processes was bilateral in 11 cases $(66.66 \%)$ and unilateral in 5 cases $(33.33 \%)$. Computed tomography also allows precise Langlais' classification. Our results are similar to those of Anh, who reports that the elongation of the styloid process is usually bilateral and the symptoms are usually one-sided [1].

\subsection{Therapeutic Aspects}

About type1 and type 2, and when the styloid process is between $28 \mathrm{~mm}$ and $35 \mathrm{~mm}$, both the external and intraoral routes are feasible. However, for this case, excision of the excess of the process is sometimes difficult by the intraoral route which offers poor exposure, and the risk of bleeding is high.

About Type1, type2 and type3, and when the styloid process measures $40 \mathrm{~mm}$ or more: the external route is preferred because, in this scenario, we found in our experience that it is difficult or sometimes impossible to identify the tip of the styloid process in the tonsillar lodge especially if it is long enough to reach the level of the hyoid bone.

The treatment was medical in one of the cases, focusing on anti-inflammatory drugs (Diclofenac: $150 \mathrm{mg}$ twice daily for 10 days); and surgical in 14 cases. Some authors propose the use of xylocaine $1 \%$ through infiltration technique, in the tonsil lodge [9]. This method would calm the pain and can serve as a test treatment. Min Kyu Han et al [23] medically treated a patient with Eagle syndrome with an initial visual analogue score (VAS) of 9. After only three weeks of treatment the VAS returned to 2. The treatment focused on a therapeutic arsenal using Gabapentin $300 \mathrm{mg} / \mathrm{d}$, Tianeptine $1.5 \mathrm{mg} / \mathrm{d}$ and tramadol hydrochloride $37.5 \mathrm{mg} / \mathrm{d}$, acetaminophen $325 \mathrm{mg}$ adding approximately $1 \mathrm{ml}$ of triamcinolone $10 \mathrm{mg}$ combined with $3 \mathrm{ml}$ of $0.3 \%$ mepivacaine injection in the tonsillar pit. Then the stellate ganglion was blocked once a week for four weeks.

The external route offers a better exposure of the surgical field, and allows to discover and resect all the process without major bleeding risk. It also allows good control of the large vessels of the neck and the facial nerve. O. Ben Gamra et al reported a case of surgically treated Eagle syndrome by approaching the styloid process by the external route [3]. Note that the use of endoscopy associated with the transoral way allows almost as clear visibility of the operating field [5]. But the external approach also allowed to perform a complementary adenectomy at the same operating time with a good exposure of the operative field, besides the styloidectomy.

Other than the classification of Langlais and the length of the styloid process, the choice of the surgical approach is also related to the complications. Hemorrhagic and infectious complications are the most frequent for an intraoral approach, whereas nerve complications (facial nerve palsy) are most frequent in the external approach. The decision to perform either approach should also take into account: pain, scarring, hospital stay, healing time, duration of the procedure, and quality of surgical field exposure [Table 3]. The adequate exposure offered by the external route is correlated with the reduction of both the duration and intensity of postoperative pain. This of course explains the short delay in hospitalization when using the external approach. Indeed, unlike pain, the operative wound can be managed externally (ambulatory care). In addition, the short surgical duration and the good exposure of the surgical field make us strongly prefer an external approach in the surgical treatment of the Eagle syndrome.

Baldé D and al [24] reported a case of Eagle syndrome that they treated surgically trans-orally. According to Baldé, this intra-oral route seems simple, fast without scarring. The study of a case of Eagle syndrome by Hossein R and al [13] reported the preferential use of the intra oral route with a complete remission of the symptoms nine months after surgery. The team of Vinod $\mathrm{K}$ and al [18] also recommends the intra-oral route and used a new technique, consisting of first approaching the styloid process at the level of the retromolar region between the rising branch of the mandible and its horizontal branch under local anesthesia. This technique seems simple and fast and the patient could return home the same day, but it does not remove the entire styloid process.

Fumihiko $\mathrm{M}$ and al [12] reported a case of trans-oral resection of the styloid process by endoscopic video-assisted approach. According to Fumihko, this technique offers a good view and lessens the risk of vascular lesions. It may be 
an alternative option in the surgical management of Eagle syndrome.

Strauss $\mathrm{M}$ and al in a comparative study between the intraoral and external route in 8 patients preferred the external route. They believe that the external route offers an optimal view and minimizes the risk of cervical infection and neurovascular injury [16]. Our study corroborates that of Strauss and concludes to clearly preferring the external route, despite the scarring that could result.

\section{Conclusion}

Eagle's syndrome is a rare condition. Its symptomatology is varied and heterogeneous. The painful palpation of the concerned tonsil's lodge is a pathognomonic sign. The diagnosis is confirmed based on the CT measurement of styloid processes that are greater than $2.5 \mathrm{~cm}$. Its curative treatment is essentially surgical with an intra-oral or external approach. We recommend the external approach in the surgical management of the affection, because it offers the best exposure of the operative field, and the control of the cervical vascular and nervous elements. The external approach also generates little postoperative pain allowing a shortening of the hospital stay. The main risks of this approach is facial nerve lesion and skin scarring.

\section{References}

[1] Anh D, Stellios K, John S. L, Roy M. F, Farhood S: Eagle syndrome presenting with external carotid artery pseudoaneurysm. Emergency Radiology. 2011; 18, 3:263-265.

[2] Farhat HI, Elhammady MS, Ziayee H, Aziz-Sultan MA, Heros RC: Eagle syndrome as a cause of transient ischemic attacks. J Neurosurg. 2009; 110, 1: 90-93.

[3] Ben Gamra O, Rhomdane N, Euch W, Abdid W, Belhadj F, Hariga I, Mbareck Ch: Le Syndrome d'Eagle. J. TUN ORLN035 JUIN 2016: 54-55.

[4] P. Pigache, C. Fontaine, J. Ferri, G. Raoul. Transcervical styloidectomy in Eagle's syndrome. European Annals of Otorhinolaryngology, Head and Neck diseases 2018; 135(6):433-436.

[5] Shilpa H, Mathew AS, Hemraj S, Sridhar A. Endoscopic transoral resection of an elongated styloid process: a case report. Int J Otorhinolaryngol Head Neck Surg 2018;4:131720.

[6] Filippo Montevecchi, Alberto Caranti, Giovanni Cammaroto, Giuseppe Meccariello, Claudio Vicini. Transoral Robotic Surgery (TORS) for Bilateral Eagle Syndrome. ORL 2019; 81(1):36-40. DOI:10.1159/000493736.

[7] Müderris T, Bercin S, Sevil E, Beton S, Kiris M. Surgical management of elon-gated styloid process: intraoral or transcervical? Eur Arch Otorhinolaryngol 2014; 271 (6):1709-13.
[8] Fusco DJ, Asteraki S, Spetzier RF. Eagle's syndrome: embryology, anatomy, andclinical management. Acta Neurochir 2012;154 (7): 1119-26.

[9] Ankit A. S, Nirali V. C, Ajay G, Kayedjihar R: Lidocine Infiltration Test: An useful test in the prediction of results of styloïdectomy for Eagles's syndrome. Indian Journal of otolaryngology and Head \& Neck Surgery. 2013; 65, 1:20-23.

[10] Faiçal Choumi, Yassine Ziani: Syndrome d'Eagle à propos d'un cas. PanAfrican Medical Journal. 2014; 18:333.

[11] Chandramani B M, Mukesh K A: Eagle's Syndrome: Report of three cases. Indian Journal of otolaryngology and Head \& Neck Surgery. 2011; 63, 4: 396-399.

[12] Fumihiko M, Kaori K, Misato K, Hiroaki K, Takako O, Katsuhisa I: Endoscopy-assisted transoral resection of the styloid process in Eagle's syndrome. Head \& Face Medecine. 2012, 8: 21 .

[13] Hossein R, Kambiz M, Mohammad D, Mina N: Complete recovery after an intraoral approach for Eagle syndrpme. J Craniofac Surg. 2010; 21, 1: 275-276.

[14] Lonka MM, Schouseboe LP: Unilateral atypical neck pain in Eagle syndrome. Ugeskr Laeger. 2012; 174, 18: 1242-1243.

[15] Sanjeev M, Thirumaran N. S, Gopinath M, Gaurav B, Shalini B: Significance of styloïdectomy in Eagles's syndrome: an analysis. Indian Journal of otolaryngology and Head \& Neck Surgery. 2009; 61, 4:262-265.

[16] Strauss M, Zohar Y, Laurian N: Elongated styloid process syndrome: intraoral versus external approch for styloid surgery. Laryngoscope. 1985; 95, 8:976-979.

[17] Vijay Chourdia: Elongated styloid process (Eagle'ssyndrome) \& Severe headache. Indian Journal of otolaryngology and Head \& Neck Surgery. 2002; 54, 3:238-241.

[18] Vinod K, Govind J, Sandeep G: Eagle's syndrome: A New surgical technique for styloïdectomy. Journal of Maxillofacial and Oral Surgery. 2015; 14, 1:360-365

[19] Haluk Y, Fatma C, Tulin Y, Levent N. O: Angulation of the styloid processus in Eagle's syndrome. European Archives of Oto-Rhino-Laryngology. 2008; 265: 1393.

[20] Piagkou M, Anagnostopoulou S, Kouladouros K, Piagkos G: Eagles's syndrome: A review of the literature. Clin Anat. 2009; 22; 5: 545-558.

[21] Eike H, Christian R, Hendrik F: Styloid-carotid atery syndrome treated srgically with piezosurgery: A case report and literature review. 2013; 43, 2: 162-163.

[22] Yoshifumi N, Kazui Y: Perioperative management of Eagle syndrome complicated by carotid artery dissection. Journal of Anesthesia. 2014; 28, 2:291-293.

[23] Min Kyu Han, MD, DO Wan Kim, MD, et Jong Jeun Yang, MD: Non Surgical Treatment of Eagle's Syndrome- A case Report. Korean J Pain 2013 April; 26, 2: 169-172.

[24] Balde D, Ayi Megnanglo A, Diallo B. K: Le syndrome d'Eagle: à propos d'un cas. Rev Laryngol. Otol Rhinol. 2015; 136, 3: 121-123. 